Research Article

\title{
A cross sectional study on the prescribing pattern, self medication and adverse reactions associated with topical corticosteroids
}

\author{
Venepalli N. Teja ${ }^{1}$, Podila K. Sree ${ }^{2}$, Venkata R. Yadala ${ }^{2}$, Arun Kumar M. ${ }^{3}$
}

\begin{abstract}
${ }^{1}$ Kamineni Institute of Medical
Sciences, Narketpally

Nalgonda, Telangana, India,

${ }^{2}$ Department of Pharmacology

Kamineni Institute of Medical

Sciences, Narketpally

Nalgonda, Telangana, India,

${ }^{3}$ Department of Dermatology \&

Venereology, Kamineni Institute

of Medical Sciences,

Narketpally, Nalgonda,

Telangana, India
\end{abstract}

Received: 08 January 2016

Accepted: 03 February 2016

*Correspondence to:

Dr. Podila K Sree,

Email: drpkarunasri@gmail.com

Copyright: (C) the author(s), publisher and licensee Medip Academy. This is an openaccess article distributed under the terms of the Creative Commons Attribution NonCommercial License, which permits unrestricted noncommercial use, distribution, and reproduction in any medium, provided the original work is properly cited.

\begin{abstract}
Background: Glucocorticosteroids, one of the common drugs used by the dermatologists brought a revolutionary change in their practice. Unfortunately steroids are misused in dermatological panacea due to dramatic relief in inflammatory and pruritic skin conditions but may lead to deleterious effects if irrationally used. Hence this study was planned to know the prescribing pattern of corticosteroids.

Methods: It was a cross sectional observational study. The prescriptions of patient attending the dermatology OPD were screened for the usage of the corticosteroids. The demographic data, chief complaints, diagnosis and the details of the drugs was collected.

Results: Out of 384 prescriptions screened, $14.06 \%$ were prescribed corticosteroids. Average number of drugs per prescription was 2.28 \pm 0.83 . Polypharmacy ( $\geq 4$ drugs) observed in $9.26 \%$ of prescriptions. Corticosteroids prescribed by generic name were $24.07 \%$ and brand name was $75.93 \%$. Corticosteroids alone prescribed in $38.89 \%$ and along with antihistaminics/antibiotics/emollients in $61.11 \%$. Topical corticosteroids prescribed in $79.6 \%$ and $20.4 \%$ by systemic route. Moderately potent steroids prescribed in $74.42 \%$ followed by potent $(13.95 \%)$ and very potent steroids (11.63\%). Patients on corticosteroid self-medication were $28 \%$, among them 4 developed adverse reactions with severe acneiform eruptions over the face. No fixed dose combination drugs were prescribed.

Conclusions: In this study we observed the rationale and safe prescribing pattern. However, the corticosteroids prescribed by brand names $(75.93 \%)$ were more than generic names $(24.07 \%)$, information about the strength of the steroid not mentioned and usage of emollients was less. This indicates the need for continuous medical education for the clinicians.
\end{abstract}

Keywords: Corticosteroids, Emollients, Prescribing pattern

\section{INTRODUCTION}

Drugs play an important role in protecting, maintaining, and restoring health, in disease conditions. However, like the two sides of a coin, we have therapeutic and adverse effects with drugs. Glucocorticosteroids, one of the commonly used drugs in the dermatological treatment brought a revolutionary change in practice. The ultimate goal in any therapy as well in dermatology is to tackle a disease or an ailment, by the safe and least possible number of drugs. Topical corticosteroids are mainly used for non-infective dermatological disorders associated with inflammations such as psoriasis, atopic dermatitis, contact dermatitis, eczema and pruritis. ${ }^{1}$ The antiinflammatory and immunosuppressant actions of these drugs increase the susceptibility to bacterial and fungal infections, hence there is an increased practice of using these drugs in combination with antibiotics and antifungals. ${ }^{2}$ In certain indications these drugs may produce deleterious effects on prolonged use or when not used for proper indication. Unfortunately steroid ointments are misused in dermatological panacea as they produce dramatic relief in inflammatory and pruritic skin conditions. The topical use of corticosteroids may result 
in adverse drug reactions like skin atrophy, striae, purpura, acneiform eruptions, hypersensitivity, telangectasias and tachyphylaxis etc. ${ }^{3,4}$

In order to minimize the adverse cutaneous reactions, rational use of topical corticosteroids requires appreciation of the physical and physiological variables like patient's age, total surface area of application, quantity to be applied and efficacy of selected corticosteroid that influences the interaction of these drugs and the skin, impacting absorption and transport. ${ }^{3}$ Hence the present study was planned with the objectives to evaluate and analyze the prescribing pattern of topical corticosteroids, their adverse reactions and selfmedication.

\section{METHODS}

It was a cross sectional observational study done in the outpatient department (OPD) of dermatology at Kamineni Institute of Medical Sciences, Narketpally, Nalgonda District, Telangana state. The duration of the study period was 6 months (May 2014 - October 2014). The study was carried out after the permission of institutional ethics committee. The subjects were included by stratified random sampling method. Prescription of every $3^{\text {rd }}$ patient of either sex, of any age attending the OPD was screened. The details of the prescriptions were taken after the written informed consent from the patients. Data was collected using a questionnaire. The demographic details were taken into consideration. Drug details, number of drugs per prescription, whether corticosteroids was prescribed or self-medicated, prescribed by generic or brand name, number of fixed dose combinations (topical corticosteroids with antibiotics / anti-fungal etc.) and their duration of use. In case of topical corticosteroids, the potency of the preparation used $\&$ the group to which it belonged was noted. Depending on the potency the topical corticosteroids were classified into 7 groups as per the American classification ${ }^{5}$ and into 4 groups by British classification. ${ }^{4}$ Also the information about any adverse reactions occurred on using the topical corticosteroids (either prescribed /self-medication) was noted. Statistical analysis was done after the collected data was expressed in Microsoft excel and analysed i.e., percentages, mean and standard deviation.

\section{RESULTS}

A Total number of 1154 patients visited the dermatology OPD during the period of two months i.e., July - August 2014. Among them, every $3^{\text {rd }}$ patient was screened for usage of corticosteroids which has come to a total of 384 prescriptions. Total number of patients on corticosteroids, either topical or systemic therapy was 54 (14.06\%). Among them 41 were males $(75.92 \%)$ and 13 females $(24.07 \%)$. The average number of drugs was $2.28 \pm 0.83$ per prescription. The maximum number of corticosteroids on a single prescription was four and the minimum was one. Polypharmacy (4 drugs) observed in $9.26 \%$ of prescriptions only. Percentage of corticosteroids prescribed by generic name was $24.07 \%$ and by brand name was $75.93 \%$.

Highest percentage of patients visiting the dermatology OPD on corticosteroids were between 11-20 years $(31.48 \%)$ followed by age group $61-70$ years $(16.67 \%)$. Age-wise distribution of the patients visiting the dermatology OPD on corticosteroids was given in Table 1.

Table 1: Age wise distribution of patients on corticosteroids.

\begin{tabular}{|lll|}
\hline Age & Number of subjects & Percentage \\
\hline $0-10$ & 3 & 5.56 \\
\hline $11-20$ & 17 & 31.48 \\
\hline $21-30$ & 8 & 14.81 \\
\hline $31-40$ & 8 & 14.81 \\
\hline $41-50$ & 7 & 12.96 \\
\hline $51-60$ & 4 & 7.41 \\
\hline $61-70$ & 9 & 16.67 \\
\hline
\end{tabular}

The subjects came with chief complaints of either itching alone $(40.74 \%)$ or itching associated with plaques/ dryness of skin/pustules/hair loss $(27.78 \%)$, or acne $(22.22 \%)$, pain in the groin $(3.70 \%)$, plaques $(3.70 \%)$ or pustules $(1.85 \%)$.

When the disease pattern was observed among the patients on corticosteroids either prescribed or selfmedicated, we found psoriasis as the common disease followed by acne and the lichen planus (Figure 1).

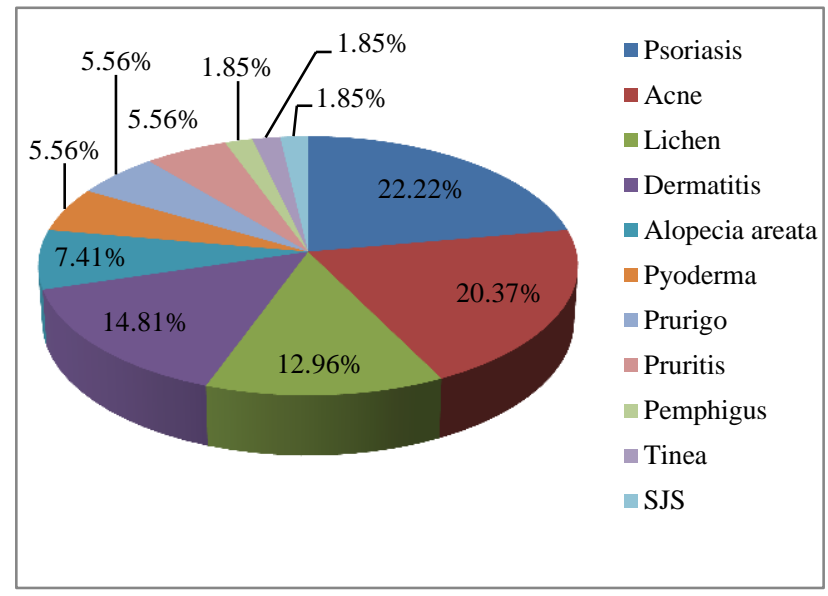

Figure 1: Utilization pattern of corticosteroids in different diseases.

We also observed that $38.89 \%$ of patients were prescribed corticosteroids alone and in $61.11 \%$ corticosteroids were prescribed along with other drugs (Figure 2). Oral antihistaminics in combination with topical/oral corticosteroids were prescribed to $37.04 \%$ of patients. Moisturizers/emollients were prescribed in 15 patients $(27.78 \%)$ along with the corticosteroids. 


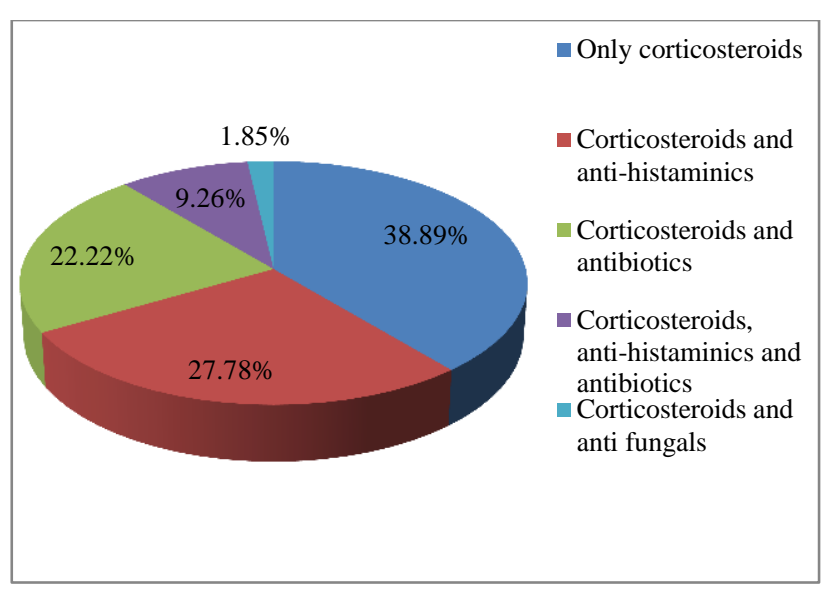

Figure 2: Prescribing pattern of corticosteroids with other drugs in dermatology department.
When the route of administration of corticosteroids was enquired, we observed $79.6 \%$ were prescribed by topical route and $20.4 \%$ by systemic route (oral $-11.1 \%$ and parenteral $-9.26 \%$ ).

The corticosteroids prescribed were Clobetasol propionate, Betamethasone, Mometasone, Clobetasone, Oral Prednisolone and Inj. Triamcinolone. We observed moderately potent steroids were used in higher percentage compared to very potent and potent steroids (Table 2).

Out of 54 patients included in the study, 15 patients $(28 \%)$ were on self-medication with the corticosteroids before coming to the OPD. Among them, 10 patients (19\%) were on Mometasone cream and 5 patients $(9 \%)$ on Betamethasone ointment. The indication for using the corticosteroids was acne in 11 patients (20\%), pyoderma in 3 patients $(6 \%)$ and tinea corporis in 1 patient $(2 \%)$.

Table 2: Prescribing pattern of topical corticosteroids based on potency.

\begin{tabular}{|lllll|}
\hline $\begin{array}{l}\text { Potency of steroid - } \\
\text { British classification }\end{array}$ & Drug & $\begin{array}{l}\text { Number of } \\
\text { patients } \\
\text { (percentage) }\end{array}$ & $\begin{array}{l}\text { Potency based on WHO } \\
\text { classification* }\end{array}$ & $\begin{array}{l}\text { Number of } \\
\text { patients }(\%)\end{array}$ \\
\hline Very potent & Clobetasol propionate & $6(13.95)$ & I (super potent) & $6(13.95 \%)$ \\
\hline Potent & $\begin{array}{l}\text { Betamethasone } \\
\text { dipropionate }\end{array}$ & $5(11.63)$ & II (potent) & $5(11.63 \%)$ \\
\hline Moderately potent & $\begin{array}{l}\text { Oint. Mometasone } \\
\text { fluroate } \\
\text { Clobetasone butyrate } \\
(0.05 \%)\end{array}$ & $32(74.42)$ & $\begin{array}{l}\text { III (Upper mid-strength) } \\
\text { Oint. Mometasone furoate } \\
0.1 \%\end{array}$ & $22(51.16)$ \\
\hline & & & $\begin{array}{l}\text { IV (Mid-strength) } \\
\text { Clobetasone butyrate }(0.05 \%)\end{array}$ & $11(23.26)$ \\
\hline
\end{tabular}

Among the corticosteroid self-medicated patients (15), four developed adverse reactions with severe acneiform eruptions over the face.

In this study we also observed that fixed dose combination drugs were not prescribed.

Regarding the instructions on how to apply, frequency and site of application of the topical drugs, we observed both the written and oral instructions were given to all the patients by the prescribers. But application in terms of fingertip units or how much quantity to be applied was explained orally.

\section{DISCUSSION}

Knowledge on prescription methodology and usage is important to ensure rational treatment with drugs. Drug utilization studies provide the insight to the drug use pattern and also give early signals of irrational usage of drugs, thereby interventions for rational drug use and continuous quality improvement can be achieved. Corticosteroids are one of the common groups of drugs used in dermatology practice. An assessment of their usage pattern is recommended to optimize the benefits, limit the adverse effects and hence the rational utilization.

The average number of drugs per prescription was $2.28 \pm$ 0.83 and was less compared to the other studies like M Ashok Kumar et al 2011 which was $8.63 \pm 1.8$ (inpatients) and $2.72 \pm 0.6$ (outpatients). ${ }^{6}$ Polypharmacy (>4 drugs) was observed in $9.26 \%$ of prescriptions only, indicating the rational prescribing of drugs.

In the present study we observed $14.05 \%$ of steroid usage falling into the range of steroid usage from previous studies. Corticosteroids usage observed in other studies was $14.2 \%$ among the inpatients and $16.10 \%$ among the outpatients by M Ashok Kumar et al, $23 \%$ by Saravana kumar et al 2012, $44.7 \%$ by Mirshad PV et al, $28.4 \%$ by Suvarna S Rathod et al and $25.06 \%$ by W.M. Sweileh. ${ }^{8-10}$ 
Most of the steroids were prescribed by brand names $(75.93 \%)$ in the present study, but of lesser percentage compared to previous studies like M Ashok kumar et al, Mirshad PV et al, where $100 \%$ brand names usage was reported. The possible reasons for prescribing drugs by brand names might be the uncertainty about efficacy of generic drugs, misconception that branded drugs being costlier are more efficacious than cheaper generic drugs, lack of information on availability of generic drugs from pharmaceutical companies, market driven forces where overworked doctors depend on the medical representatives who promote their drug concealing the negative effects. But in reality, it was proven in many studies that most of the generic drugs are equally efficacious as the branded drugs. ${ }^{11}$

In the present study, the usage of very potent steroids $(13.95 \%)$ was less than the moderately potent steroids (74.42\%) whereas Suvarna S Rathod et al and Mirshad PV et al reported usage of higher percentage of very potent steroids $94.36 \%$ and $50 \%$ respectively. In another study by Sravana Kumar et al reported $100 \%$ usage of potent and very potent steroids.

In our study, there was no usage of fixed dose combination drugs indicating the rational prescribing of drugs which was according to the WHO guidelines of rational prescribing.

In this study the strength of the steroid prescribed was not mentioned on the prescription. The reason for not specifying the strength may be because of prescribing the drugs by brand names $(75.93 \%)$, where they are available as single strength preparations.

The other important aspect in the usage of topical corticosteroids is how much quantity to be used. Not specifying the quantity can result in either under-usage or over usage subsequently results in sub-therapeutic outcome or unwanted effects. This lefts the patient confused and even anxious - about using the preparations that have been prescribed. This was observed in previous studies also like Mirshad PV et al, Suvarna S Rathod et al, W. M. Sweileh where they reported that the information about strength, duration and quantity of steroid to be used was inadequate in most prescriptions. But oral instructions were given in our study.

To rationalize the advice on applying topical therapy many attempts were made, the method that gained widest acceptance is the fingertip unit (FTU). ${ }^{12}$ FTU is the amount of cream or ointment expressed from a 5-mm diameter nozzle, applied from the distal skin-crease to the tip of the patient's index finger can be used to calculate how much product is needed to cover affected areas, and hence the quantity which should be prescribed. It has the advantage of automatically correcting for body size: thus one FTU (approximately $500 \mathrm{mg}$ ) is sufficient to cover two adult palms. Clear explanations makes the patient aware of how much steroid to use, where and when to apply it, and for how long to use it, as the risk of sideeffects increases with steroid potency and the quantity used. Hence the dermatologists should be sensitized regarding the usage of FTU while prescribing the corticosteroids to avoid adverse effects.

In this scenario, one can cut down the usage of steroids by prescribing them along with emollients. Emollients were prescribed in only 15 patients $(27.78 \%)$ along with the corticosteroids, even though many studies reported their steroid sparing effect i.e., the ability to reduce the need to use topical steroids especially in patients with atopic eczema and psoriasis. ${ }^{13,14}$ Therefore it is essential for all the practicing clinicians to have regular continuous medical education programmes to update their knowledge which helps in rational prescribing of medicine.

The strength of the study was patient selection by stratified random sampling thus eliminating the selection bias that influences the study outcome. The limitations of the present study were the short duration of the study period, small sample size and as it was a cross sectional study we could not assess the safety and efficacy parameters of topical corticosteroids.

\section{CONCLUSION}

In the present study we observed that most of the patients were prescribed formulations containing steroids alone which are moderately potent steroids (74.42\%) suggesting the rational prescribing. Further, the prescribing pattern was safer as no adverse effects were reported due to corticosteroids during the study observation period. However, the prescriptions contained brand names $(75.93 \%)$ more than generic names $(24.07 \%)$, information about the strength of the steroid was not mentioned and usage of emollients was less. This indicates the need for continuous medical education for the practicing physicians.

\section{ACKNOWLEDGEMENT}

We thank the Department of Pharmacology, Department of Dermatology and Venereology, management of Kamineni Institute of medical sciences and the participants of the study, for their support in completing this study. We also thank ICMR, New Delhi for accepting this project under short term studentship project - 2014 .

Funding: ICMR - STS

Conflict of interest: None declared

Ethical approval: The study was approved by the Institutional Ethics Committee

\section{REFERENCES}

1. Ference JD, Last AR. Choosing Topical Corticosteroids. Am Fam Physician. 2009;79:135-40. 
2. DSouza P. Rational and ethical use of topical corticosteroids based on safety and efficacy. Indian $\mathbf{J}$ Dermatol. 2012;57(4):251-9.

3. Craig N. Burkhart, Lowell A. Goldsmith Dean S. Morrell. Dermatological Pharmacology. In: Laurence L. Brunton, editors. Goodman \& Gilman's The Pharmacological Basis of Therapeutics $12^{\text {th }}$ ed. McGraw-Hill Companies, Inc. China. 2011.

4. Sathoskar RS, Bhandarkar SD, Nirmala NR. Pharmacology and Pharmacotherapeutics. $23^{\text {rd }}$ ed. Noida : Popular prakashan. 2013:916-8.

5. Jacob SE, Steele T. Corticosteroid classes: a quick reference. J Am Acad Dermatol. 2006;54:723-7.

6. Kumar AM, Noushad PP, Shailaja K, Jayasutha J, Ramasamy C. A study on drug prescribing pattern and use of corticosteroids in dermatological conditions at a tertiary care teaching hospital. Int $\mathrm{j}$ pharm sci rev res. 2011;9(2):132-5.

7. Saravanakumar RT, Prasad GS, Ragul G, Mohanta PK, Moorthi C. Study of prescribing pattern of topical corticosteroids in the department of dermatology of a multi-specialty tertiary care teaching hospital in South India. Int. J. Res. Pharm. Sci. 2012;3(4):685-7.

8. Mirshad PV, Khan AKA, Rahiman OMF, Muneersha TKM. Prescription audit of corticosteroid usage in the department of dermatology at a tertiary care teaching hospital. Int $\mathbf{J}$ Basic Clin Pharmacol. 2013;2:411-3.

9. Rathod SS, Motghare VM, Deshmukh VS, Deshpande RP, Bhamare CG, Patil JR. Prescribing practices of topical corticosteroids in the outpatient dermatology department of a rural tertiary care teaching hospital. Indian J Dermatol. 2013;58:342-5.

10. Sweileh WM. Audit of prescribing practices of topical corticosteroids in outpatient dermatology clinics in north Palestine. East Mediterr Health J. 2006;12:161-9.

11. World health Organization: Facts about Generic Drugs. Available from: http://www.fda.gov/drugs/resourcesforyou/consumer s/buyingusingmedicinesafely/understandinggenericdr ugs/ucm167991.htm

12. Bewle A. Dermatology Working Group. Expert consensus: time for a change in the way we advise our patients to use topical corticosteroids. $\mathrm{Br} \mathrm{J}$ Dermatol. 2008;158(5):917-20.

13. Harcharik S, Emer J. Steroid-sparing properties of emollients in dermatology. Skin Therapy Lett. 2014;19(1):5-10.

14. Moncrieff G, Cork M, Lawton S, Kokiet S, Daly C, Clark C. Use of emollients in dry-skin conditions: Consensus statement. Clin Exp Dermatol. 2013;38(3):231-8.

Cite this article as: Teja VN, Podila KS, Yadala VR, Kumar AM. A cross sectional study on the prescribing pattern, self medication and adverse reactions associated with topical corticosteroids. Int J Basic Clin Pharmacol 2016;5:429-33. 